\title{
Urban plaza design process using space syntax analysis:
}

\author{
El-Houria plaza, Biskra, Algeria
}

\author{
Souhaila Bendjedidi ${ }^{*}$, Yassine Bada ${ }^{1}$ and Rim Meziani ${ }^{2}$ \\ 1 Laboratory of design and modeling of architectural ambiances and urban forms \\ (LACOMOFA), Departement of Architecture, Mohamed Khider University \\ 2 Department of Architecture and Design, Abu Dhabi University \\ *Corresponding Author, Email: $\underline{\text { S.bendjedidi@hotmail.com }}$
}

Received: September 26, 2018; Accepted: November 29, 2018

Key words: Urban Plaza, Design Layout, Space Syntax, Visibility, Accessibility.

\begin{abstract}
The quality of urban public space in general, and urban plazas in particular, has been a concern and a major challenge for designers in setting rules and principles to its layout and its design; functional and aesthetic.

Environmental and behavioural research contributes importantly to the understanding of the interaction between user and space, to well respond to users' real needs; and to have design grounded in social understanding. In pertinent literature, it is common to argue that the most important measures of the success of an open space is attributed to its location, design, and use. In this matter, space syntax provides theory and method to analyse the correlation between spatial properties and people behaviour; understanding this interaction helps in design, with improved design leading to more functional places.

This paper instigates from the assumption that human behaviour in space is highly dependent on visibility generated by the built environment configuration, and it aims to look into the correlation between the use of space and spatial quantitative measures, i.e. the syntactic properties of an urban plaza. It also aims to look into how to integrate space syntax analysis as a tool in the plaza layout design process. This work will be carried out on the analysis and the design proposal of the most frequented public place in Biskra, Algeria, "El-Houria plaza". The analysis process consists of overlapping space syntax method (Depthmap), behaviour mapping and various qualitative analysis techniques such as questionnaire and mental mapping. The results show that plaza spatial use is highly dependent on visibility and that the accessibility (visual access) and the connectivity to the surrounding are the key parameters to its functioning. The results also indicate that there is a high correlation between the human behaviour and the syntactic properties in selecting places to do definite activities. Furthermore, it is shown how visibility becomes the principal feature in the layout proposal of this plaza.
\end{abstract}

\section{INTRODUCTION}

Urban public spaces are fundamental elements of the urban environment and the aesthetic appearance of the built environment, which have always played a key role in the structure, organization and public life of the city. 
Urban plaza is one type of open public space, considered as the first discovered by man as a result of grouping a cluster of houses around an open space (Krier \& Rowe, 1979), also as an ideal stage for the collective representation of urban society that reflects a city's identity and the communities' cultural background. Today, many public plazas are nonfunctional spaces, barely used or unevenly used; this is due to various deficiencies that are mainly relevant to their layout design and site organization (Whyte, 1988).

There are two main methods of categorizing the plaza, by function and by form (Moughtin, 2003). Some research focuses more on the spatial organisation and the visual effects rather than the functionality, leading to dysfunctional spaces with a negative impact on people's lives. However, others suggest that functionality comes first in urban plaza design. In this regard, the functionality and the form of the plaza are two equally important criteria that should not be neglected in the design process. In fact, the relationship between these two dimensions determines the character and success of the urban plaza (Özyavuz, 2013).

Several environmental and behavioural studies have contributed importantly to the understanding of the interaction between user and space, to well respond to users' real needs, to have design grounded in social understanding. In pertinent literature, it is common to argue that the most important measures of an open space's success is attributed to its location, design and use. Many theoretical concepts, evaluative methods and tools have been developed to investigate this issue. This study relies on space syntax as an analytical and design tool in the process of a design proposal of the main existing public plaza in Biskra, Algeria, "El-Houria plaza". Thus, to show how space syntax could be a remarkable tool to be integrated into the design process. Like many urban plazas, public plazas in Biskra, despite some layout design attempts to make them more functional and responsive to people needs, they are still dysfunctional spaces and rarely used. To look into this matter, this work illustrates how plaza layout design could affect its use and how to make it more functional and attractive, focusing on syntax properties of space, i.e. visibility.

\section{RESEARCH FRAMEWORK AND METHODOLOGY}

\subsection{Human behaviour and perception of public space}

Understanding the use of space by humans has become a necessary analytic step in the design process (Baker, 1997). The perception of space describes the multiple ways in which people receive information from their surroundings, to know their space. The impression of space is a construction of human perception (mainly visual) and a cognitive system that actively forms relations between objects or relations (Bada, 2012). So, the comprehension of human behaviour and the perception of space represent the principal way to improve the quality and the functionality of public space.

To understand what makes the success or failure of some plaza designs in New York City, Whyte (1980) observed in-situ and recorded the behavioural dynamics of plaza use. He found that people choose to occupy 
dense spaces (co-presence), pedestrian paths and flows, deducing that the main activity for people is to look at other people; what attracts most people, are other people. He concluded that visibility increases the sense of security that is highly preferred by people.

Lynch (1976), in dealing with the perception of urban space, suggested that the design and planning of urban spaces should be based on people's experience and the ways in which space could be more legible. Gehl (1987) has similarly focused on the social interactions and human behaviour related to perceptions of public spaces. He argued that the presence of people is the key feature of a public space that can be encouraged through physical planning. According to him, people prefer to occupy the curbs (edges and pillars), especially places where people could sit and face the pedestrian flows. That means people prefer areas which provide good visibility, but with keeping some privacy: 'edge effect'.

\subsection{Theories in urban design}

Most theories and research tend to stress the importance of the realities that people live and treat their experiences of their everyday activities as a feedback to designers to adapt the design process and to create better space, thus being more human and responsive to these realities, instead of concentrating solely upon the physical environment, as Husnéin (2017) stated, "everyday life is connected to urban design through everyday experiences of physical space".

Understanding people's behaviour in space, the way they use and colonize space, is a requisite to build a substantive knowledge (Lang, 1987). To deepen this issue, Alexander (1977) introduced the term 'tendencies' (observable patterns of behaviour) to replace the idea of 'needs' of people. He states that the environment is supposed to carry out these tendencies as well as conflicts between these tendencies. He argued that these conflicts must be treated by the geometrical relationship of the environment features as the sole key to a successful design. He also advocates for the integration of social and environmental criteria into the design process. Perin (1970) also stressed the importance of analysing human behaviour and invented the term 'behaviour circuit' to refer to the observation of people's everyday activities and behaviour in order to; "learn what resources, physical and human, are needed to support, facilitate or enable them".

Hillier (1996) emphasized the importance of the correlation between the visual properties of space and people behavior; static or dynamic (movement). He argued that the spaces preferred and occupied by people are those characterized by the visual properties experienced by the stationary person. He added that space depends primarily on 'how to deploy physical elements'; the arrangements of boundaries and walls, and the consequent generated visual field that affects people's behaviour, this constitutes the everyday life real space that is 'rarely itself that is addressed'. Talking about urban space, he stated the city is composed of two cities: the physical city and the experiential city in which the spatial network and space is the common medium. The physical city refers to buildings and all physical objects, and the experiential city is the space between them for the movement that spatially merges into one; its layout design could affect its experience (Hillier, 2005). 
It seems that most theories and concepts tend towards a consensus: a 'substantive theory' that deals principally with the man-environment issue that requires an understanding of the natural and the built environment and their relationships to people's lives, instead of a normative theory that deals with "what has been consensually agreed upon, the norms of a given time or what to be - what a good world is" (Lang, 1987). In other words, to approach with a design based on users' experience.

\subsection{Space Syntax application}

The space syntax emerges as a set of theories and methods used for the definition of the structural environment and analysis of spatial configurations. At the end of the 1970s, space syntax was first put forward and applied by Bill Hillier and his team. Since then, many scholars have conducted a number of extension studies on space syntax, such as the studies on urban traffic, urban street layout, urban space design, and so on. Space syntax is another way of thinking about space by focusing on the organization of spaces, movement patterns and their social meanings (Dursun, 2007), and this has been chosen to be used by this research to investigate the case study mainly because it provides techniques and tools that allow analysis and quantification of space, and also to link its configuration (spatial aspect) with people's behavior (social aspect).

The application of space syntax has been used to study several issues and its techniques are very much applied in contemporary studies that deal with the impact of urban form (visibility features) on spatial use and human behaviours in urban plazas. Hillier (1996), in studying a number of open spaces in the City of London, discovered that the areas with heavy traffic are better used than those without traffic and that open places are better than those which are closed; the more space is structured and legible, the better it is lived by the user. Campos, B. (1997) carried out a comparative study of twelve plazas in London, based on three levels: 1) the closure (visual link with the surroundings), 2) syntactic measures, and 3) the number of static people. The results showed that the performance of plazas is related to the provision of places to sit, well-designed elements, and that enclosure is not particularly significant. It was also found that the number of static people using the plaza is not only dependent on the number of axial lines that interface with the public space, but to the sum of its global and local integration values. In another work, she investigated the relationship between visual fields and patterns of stationary activities for six public plazas in London, using people counting, observation and the space syntax method. The results indicated that people avoid very exposed areas and prefer spaces providing views, so the need of the ability to see is present, but the degree of seclusion depends on the person himself (Campos, M. B. d. A. \& Golka, 2005). Bada (2012) has studied four plazas within the city centre of Biskra, Algeria, to look into why, within the same plaza, some parts are busier and more preferred by people than others. He investigated the correlation between people's movement and spatial use to the visual fields created by the spatial configuration. The results showed that people come to public space through linear properties and then choose the location that offers some privacy, so the spatial use is strongly related to visual considerations relevant to the type of activity. Trova, Vaso et al. (1999) have studied how the visual fields, linear properties, and socio-spatial boundaries interact to structure the public space of three sets of housing in Athens using syntactic and isovist analysis. The results showed that people converge on 
the areas of the greatest visual field and the correlation between the density of people moving and syntactic variables are higher. In analysing the proposals of Omonoaia plaza (Athena) design completion laureates, Trova has focused on the visual aspect and its impact on the functioning of space. She stressed the importance of the visual fields created from the relative position of architectural elements, and how these were not integrated into the design process of the proposal entries (Trova, V, 2007).

\subsection{Overlapping space syntax to qualitative methods}

Against this backdrop, this paper instigates from the assumption that human behaviour in space is highly dependent on visibility generated by the built environment configuration, and it aims to look into the correlation between the use of space and spatial quantitative measures, i.e. the syntactic properties of an urban plaza, and how to integrate space syntax analysis as a tool in the plaza layout design process. This work will be carried out on the analysis and the design proposal of the most frequented public place in Biskra, Algeria, "El-Houria plaza". The research methodology is constituted of three phases (see Figure 1), the first is an analysis of the existing plaza layout, which consists of overlapping space syntax method (Depthmap), behaviour mapping and qualitative analysis techniques such as questionnaire and mental mapping, to assess whether there is any correlation between the space use and the spatial properties of a given space in the plaza; to look for links between visibility and spatial use. The second is a design principles implementation, which is based on the results obtained by the current plaza analysis, particularly the syntactic ones, and the last is a syntactic evaluation of the plaza layout design proposal carried out to check whether the spatial proprieties of different subspaces are relevant or not to design principles, through three analyses: visibility graph, fewest-lines and isovist, using the Depthmap program.

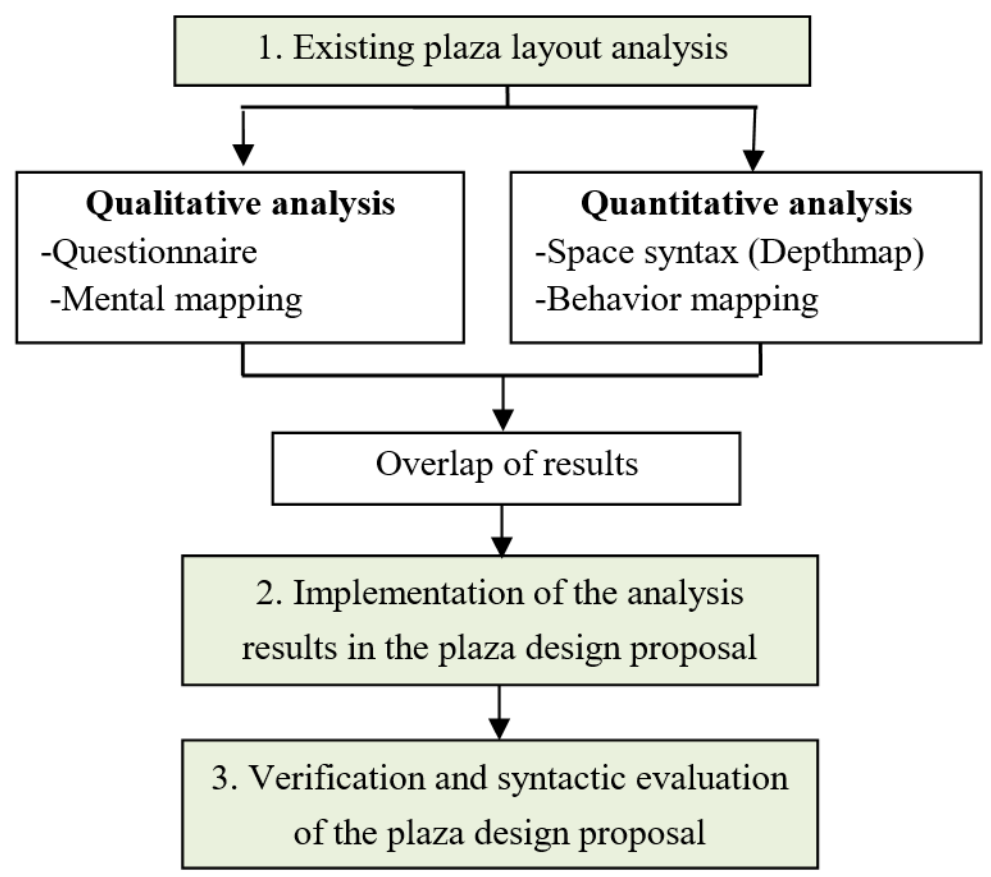

Figure 1. Research methodology diagram; analysis and design process of El-Houria Plaza. 


\section{CASE STUDY}

Biskra is a mid-sized city in the Southeastern part of Algeria, located on the edge of the Sahara Desert in a stretch of oases, around $430 \mathrm{~km}$ south of Algiers, it is known as the 'gate to the desert' with very hot summers and mild winters. Biskra has several open spaces such as plazas and public gardens. El-Houria plaza has been chosen essentially as a case study, for its strategic location in the city centre (Figure 2), and which allows it to be among the most popular plazas in Biskra; where occasionally various celebrations and festivities are held.



Figure 2. Situation plan of El-Houria plaza in Biskra city.

Two main busy streets go parallel on two opposite sides of the plaza (Figure 3). The plaza layout is mainly characterized by its two-level space; the higher part limited by Elamir Abdelkader Boulevard, the most liveable street of the city, and the lower part is limited by a busy street that links to a popular market. The difference between the two levels is about 1.20 meters in height, and the connection is assured by a series of stairs. The space layout is characterized by a linear fountain along a central pathway oriented symmetrically to the state building facade, a memorial wall and well-defined spaces by built sitting areas. Surrounding land uses include cafes, few shops, and newsstands. 



Figure 3. (A) Ground plan of El-Houria plaza, (B) Photo taken at the higher level of the plaza, (C) Photo taken at the lower level of the plaza.

\section{DESIGN PROCESS}

The design process is based on three steps: analysis of the existing plaza layout, design principles implementation, and syntactic evaluation of the plaza layout design proposal.

\subsection{Analysis of existing plaza design}

First, the goal of this analysis phase is to investigate the pattern of occupation of the plaza (existing layout) inherent to stationary and nonstationary activities or positions: sitting, standing people, and moving people. Second, is to look if there is any correlation between the space use and the spatial properties of a given space in the plaza; to look for links between visibility and spatial use. Therefore, the main focus is put on the visual fields created by urban components and architectural elements in the plaza layout and their impact on the plaza use. So, to know in detail the distribution of people and the occupancy of space throughout all the subspaces of the plaza and their syntactic properties, the analysis phase is based on various qualitative and quantitative analysis techniques. 


\subsubsection{Use of questionnaire and mental mapping}

Questionnaire and mental map techniques are used to grasp any connection between the people's perception and use frequency of the plaza. The questionnaire consists of a series of questions addressed to 100 users about the use pattern and frequency of the plaza. The results showed that $70 \%$ of respondents have considered it as a place of crossing, with a shorter length of stay, due to many problems related to its design such as the lack of green spaces, playgrounds, and family spaces, and also the lack of comfort.

In order to grasp people's mental representation of the plaza, two mental mapping exercises are carried out. Firstly, a group of thirty participants is asked to draw on a sheet of paper all the public plazas of Biskra city they know or visited, to find out if El-Houria plaza is popular and well-known in the city or not. Secondly, the same participants who know or visit the plaza are asked to draw the layout of EL-Houria plaza and represent its features as much as possible, to grasp what is mostly noticable and attracts people (Figure 4). The main finding is that El-Houria plaza is the most popular public plaza in the city, the most cited and the better represented by participants. The elements that stand out from the mental maps as the most attractive in the plaza are: the fountain, the memorial wall and the monument (Figure 5). Moreover, these elements drawn by the respondents do not point to any activity, meaning the plaza does not provide such affordance.

The confrontation between the mental mapping and the questionnaire results leads to the same conclusion that El-Houria plaza is considered just as a crossing place due to several problems linked to its layout design, and also the majority of users find it unpleasant, not functional and visually not attractive.



Figure 4. Examples of mental maps of EL-Houria plaza drawn by the respondents.
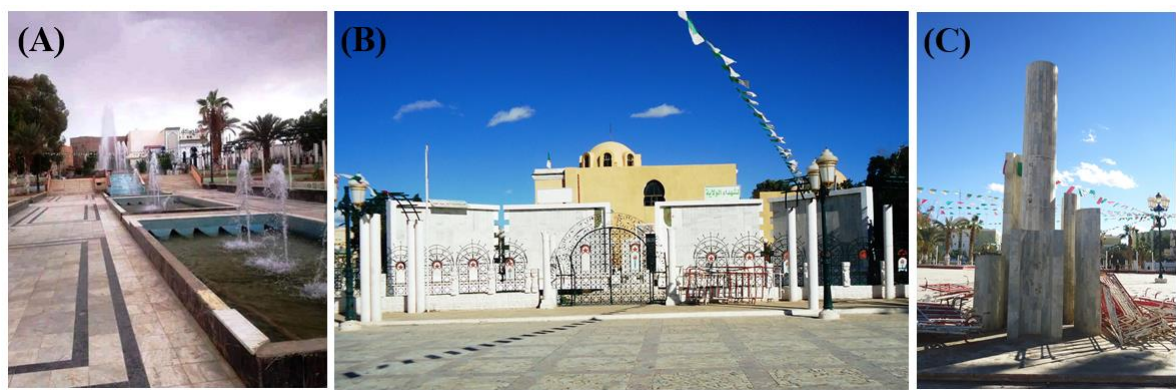

Figure 5. The three elements that stand out from the mental maps as the most attractive in ElHouria plaza: A) The fountain, B) The memorial wall, C) The monument. 


\subsubsection{Use of behaviour mapping}

The large size and non-visibility between parts of the plaza itself (due to the obstruction of physical elements such as trees, memorial wall, and monument) would make observations inaccurate. As a result, the plaza is subdivided into subspaces, using some physical objects as landmarks for their delimitations. The main physical property that determines the subspaces is the level difference of 1.20 meters. The upper level is subdivided into two subspaces, 1 and 2 , by the presence of the memorial wall, while the lower space is subdivided into three subspaces, 3,4 and 5, by the built-in sitting benches and a row of boutiques (Figure 6). Peoplecounting considered only static people (sitting and standing positions) and dynamic people (people in activity with corporal mobility), while eliminating people crossing the plaza. For the present work, the goal is to look for any link between occupancy of space and the properties of that space no matter the type of people's activities.

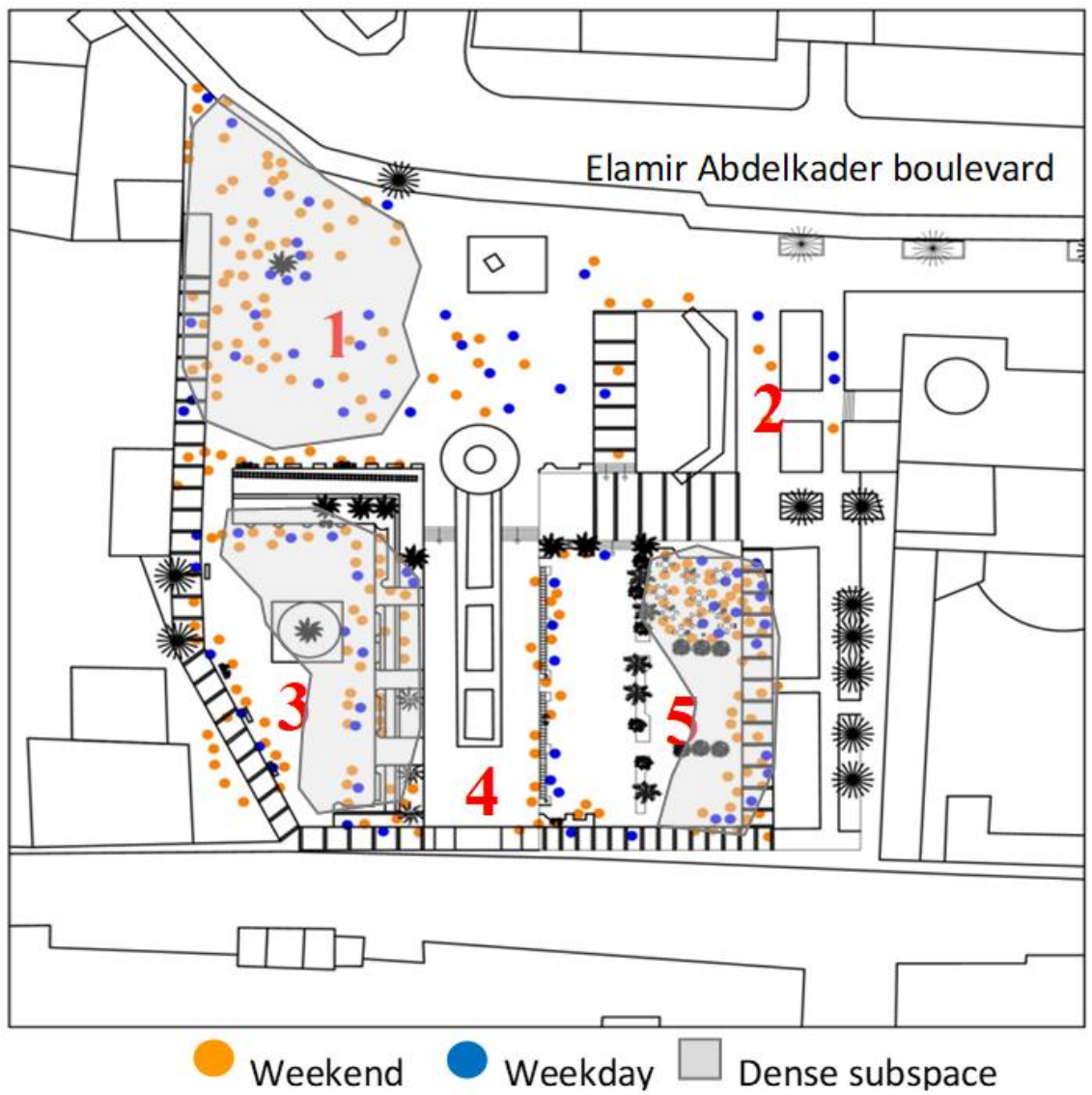

Figure 6. Behaviour map of static (sitting/ standing), and dynamic (in an activity) people of El-Houria plaza. People on the map are represented by dots. 
Table 1. Shows the number of static people (sitting/standing people) and dynamic people, according to subspaces of El-Houria plaza on two days (a weekday and a weekend day).

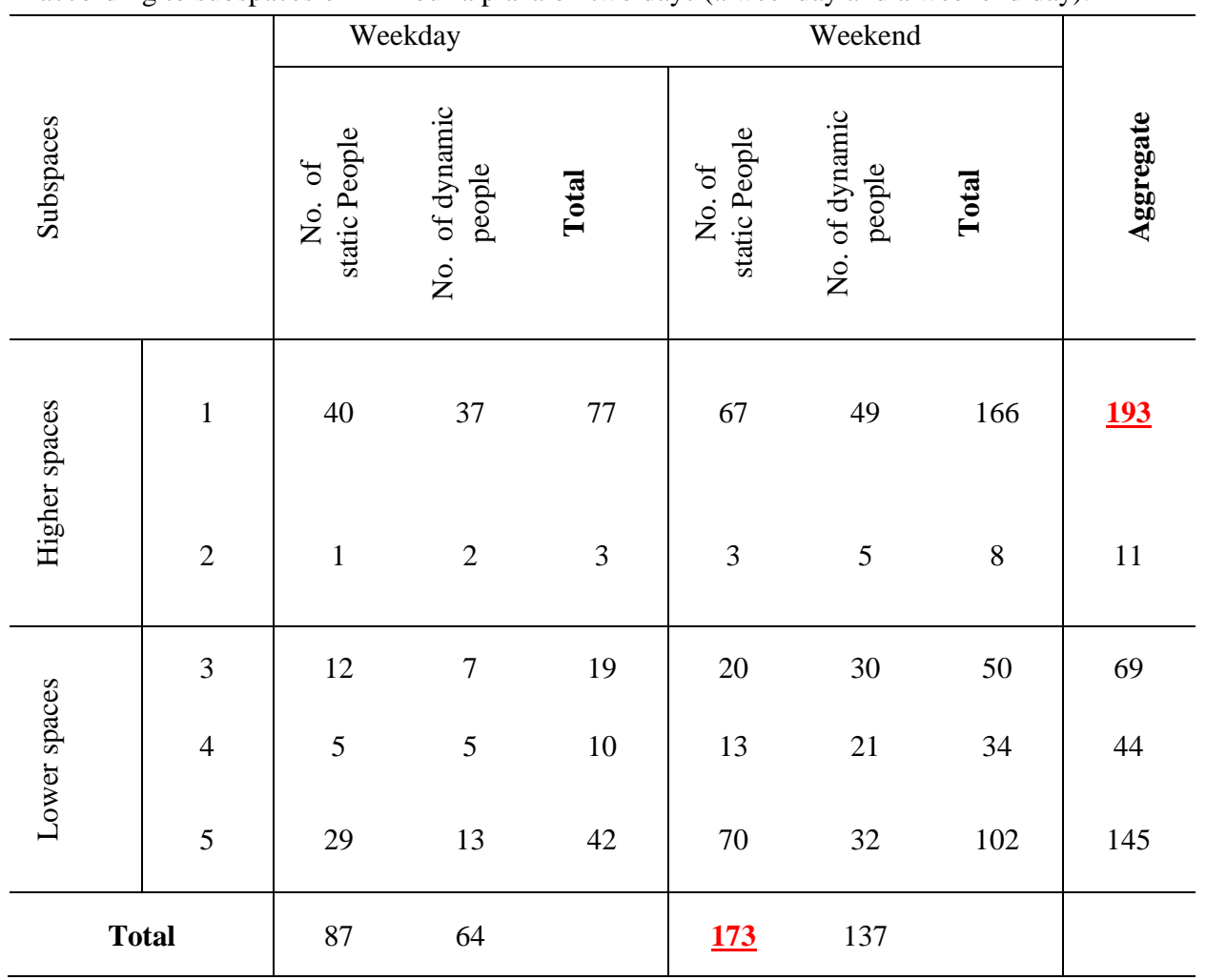

The first assessment about the behaviour mapping of the spatial occupancy of the plaza Table 1 shows that the space occupancy of the upper zone, which is connected to a major street, is remarkably higher than the lower zone mainly on the weekend.

\subsubsection{Use of space syntax}

Afterward, El-Houria plaza is modelled by space syntax techniques, using "Depthmap" program which is considered as a visual analytical tool (Turner, 2004), to explain the relationship between accessibility, visibility, and movement of users.

\subsubsection{Visibility analysis}

In term of visual analysis, isovists and Visibility Graph Analysis (VGA) of the plaza (existing layout) are generated to grasp the syntactic values, i.e. integration and connectivity values of different subspaces of the plaza. The integration value is calculated to measure how well integrated the subspaces are, that is, limited only to the boundary of the public plaza. However, the connectivity value is used to indicate how visually attractive is the plaza from its surrounding, and how connected it is with the other adjacent spaces; a 250 meter-radius surrounding area has been considered, from the centre of the plaza, in order to track their movement trajectories. 

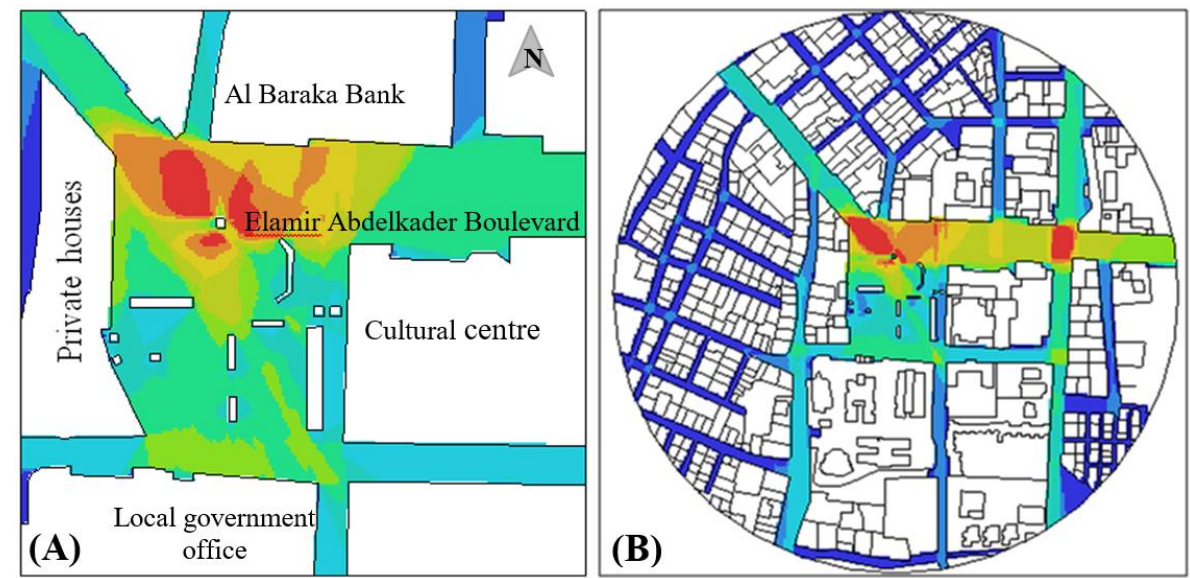

Figure 7. (A) Results of the VGA for the visual integration values of El-Houria plaza, (B) Visual connectivity within a 250 meter-radius perimeter from the centre of El-Houria plaza. $($ Red $($ the darkest colour $)=$ high values $/$ blue (lightest colour $)=$ lower values $)$.

As can be seen on the Visibility Graph Analysis (Figure 7), the value distribution of integration and connectivity are very close. The most connected areas (significant value over 11,280), and the most integrated (maximum value 28.76) are located in the north, near the Elamir Abdelkader boulevard. These spaces are visually exposed, accessible, and well connected to other areas of the plaza and to the adjacent urban spaces. Therefore, they must be highly considered in the plaza layout design.
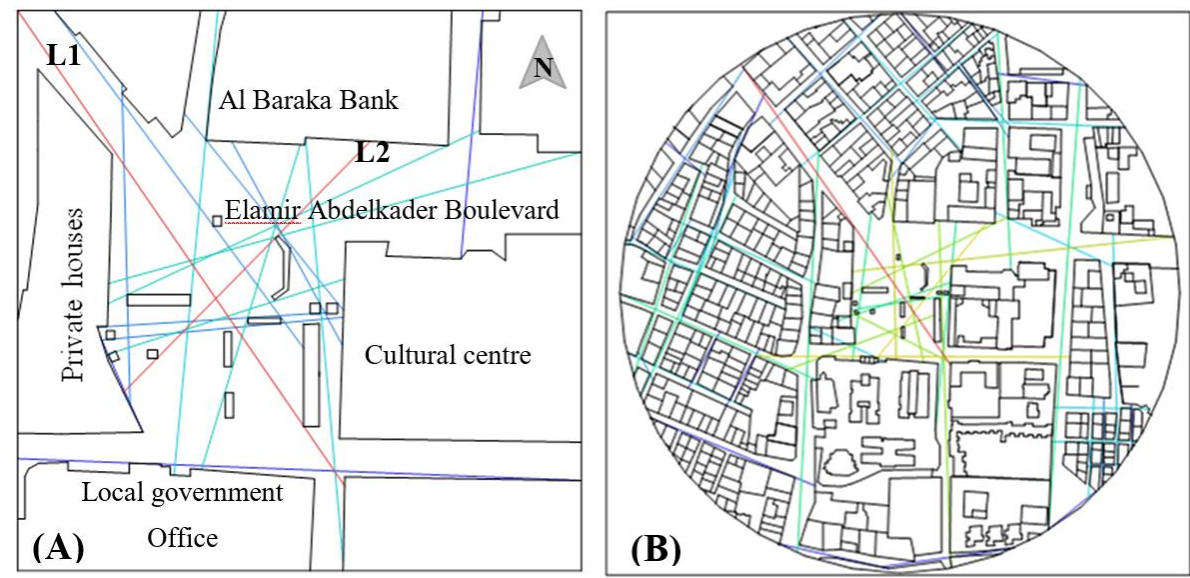

Figure 8. (A) Results of the fewest-lines analysis for the visual integration values of ElHouria plaza. (B) The visual connectivity within a 250 meter-radius perimeter from the centre of El-Houria plaza. (Red (the darkest colour) $=$ high values / blue (lightest colour) $=$ lower values).

The axial map (Figure 8) highlights two major lines (L1; L2) that are the most integrated and connected lines, where the line (L1) is characterized by its length. This predicts the importance of these lines' directions in the design proposal.

Isovists are generated from two points; from the esplanade in the subspace 1 (higher level) as an entry to the plaza from Elamir Abdelkader Boulevard, where space is more integrated, and from a point in the subspace 3 (lower space), where the space is segregated, to measure and compare the visual potentiality of both points as experienced by users. This analysis has considered only the geometric shape of the polygon (Figure 9). 



Figure 9. Isovists generated showing the visual potentiality, (A) from the esplanade (subspace 1), (B) from the subspace 3 .

According to Figure 9 (A), the plaza is visible, except for subspace 2 behind the memorial wall and subspace 3 , due to the visual obstructions such as trees and the memorial wall. From the isovist map (Figure 9 (B)), partial visibility can also be noticed from the generating point, because of random tree plantings covering the view and the memorial wall hiding subspace 2 .

\subsubsection{Overlap of behaviour map and visual integration map}

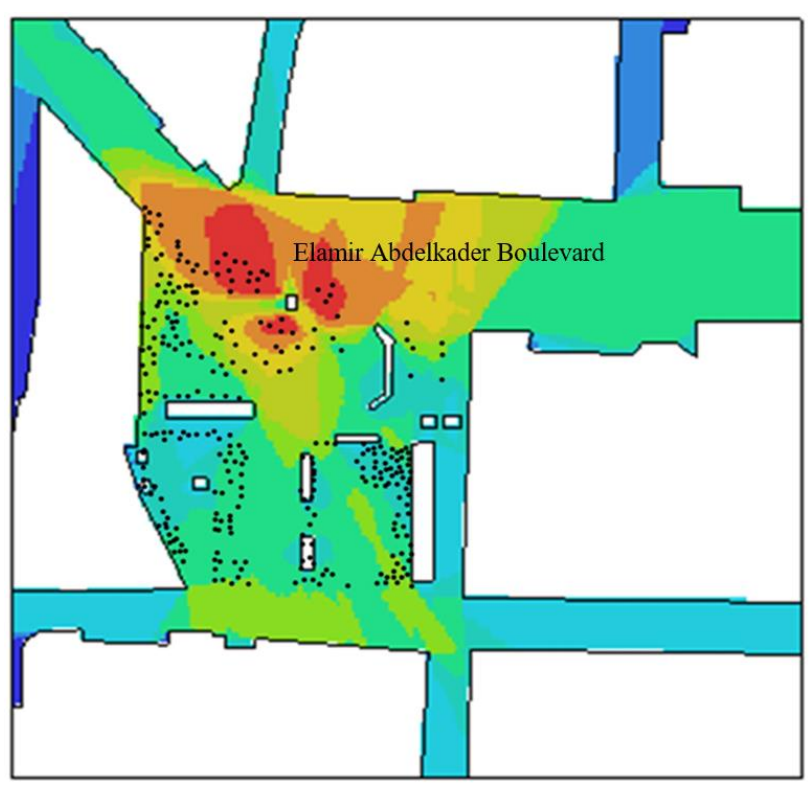

Figure 10. Overlapping people's spatial occupation and visual integration map. (Red (the darkest colour) $=$ high values $/$ blue (lightest colour) $=$ lower values). Static and dynamic people on the map are represented by dots

The overlapping of the behaviour map with the visibility graph shows that there is a correlation between the integration value and occupancy of space (Figure 10); the higher is the integration value, the greater is the number of users occupying space (Table 2); occupying the most visible and accessible areas. These results indicate that there is a high correlation between the human behaviour and the spatial syntactic properties in selecting places to do definite activities. To sum up, visual access and 
visibility are two parameters that influence people's movement in space and therefore in choosing a given space for a given activity. As it can be seen in the results, the layout of the plaza does not handle these parameters as it should due to the visual obstructions between subspaces, such as the random distribution of trees and the location of the memorial wall that is as a visual shield, in addition to the quality of the urban furniture in the plaza, which does not invite people to use it. Hence, the plaza, despite its good location in the urban structure with good connectivity, is not functional and not frequented by people as it should be. This is due to its layout design that has weakened its spatial urban quality (syntactic), as has been demonstrated.

Table 2. Showing the number of static (sitting/standing) and dynamic (in an activity) people in each subspace with space syntax values (integration and connectivity).

\begin{tabular}{|c|c|c|c|c|c|c|}
\hline \multicolumn{2}{|c|}{$\begin{array}{l}\tilde{\Xi} \\
\tilde{\tilde{n}} \\
\tilde{0} \\
0 \\
\tilde{\Xi}\end{array}$} & 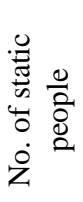 & 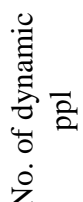 & 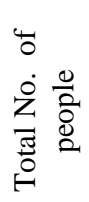 & 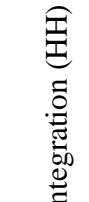 & 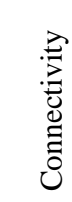 \\
\hline \multirow{2}{*}{  } & 1 & 67 & 49 & $\underline{166}$ & 20.94 & 2349 \\
\hline & 2 & 3 & 5 & 8 & 11.54 & 1244 \\
\hline \multirow{3}{*}{ 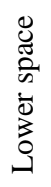 } & 3 & 20 & 30 & 50 & 12.31 & 1186 \\
\hline & 4 & 13 & 21 & 34 & 11.81 & 1259 \\
\hline & 5 & 70 & 32 & 102 & 12.63 & 1309 \\
\hline
\end{tabular}

\subsection{Implementation of the analysis results in the plaza design proposal}

This study is a research work on urban plaza analysis using space syntax, and a layout design proposal based on the analysis results and on syntactic principles (space syntax theory). This design proposal is also intended to be a pedagogic sample of introducing space syntax into the design process and may be a proposed for consideration at the local municipality level.

The plaza design aims to provide a dynamic and functional space by creating a new image of the city of Biskra and to achieve a flexible space for walking, based on visibility features. The design process was based on the results obtained by the current plaza analysis, especially on the syntactic properties (Figure $11(\mathrm{~A})$ ), where the initial idea was a superposition of three specific structures (Figure 11 (B)). The first structure is a pedestrian axis created by a regular square grid pattern of $20 \mathrm{~m}^{2}$ shifted at an angle following the most integrated lines L1 and L2 (axial line). The second one is a grid of services conceived on the basis of a cube of $5 \mathrm{~m}$ and arranged according to a regular square grid of $10 \mathrm{~m}^{2}$. Every cube is unique and formally different, some are designed to house services such as cafeterias and staircases to the underground parking. These cubes' design (volume) and position are dictated by visibility considerations in order to avoid the effect of visual obstruction as found in the existing layout. Finally, the interconnected footbridges are created on the two most connected and integrated axis according to the axial map of the syntactic analysis and which indicate the directions of movement, being the paths potentially 
interesting for the plaza design as links to the surrounding areas. The most integrated spaces, according to the VGA results in the north of the plaza, were liberated as an esplanade with a memorial wall, designed in a way that did not hinder their visibility (Figure $11(\mathrm{C} ; 2)$ ), in order to create a wide visible area attracting people to access the plaza. Concerning the segregated spaces, a cultural space was created as an extension of the existing cultural centre, and a green space created with trees as a small garden for resting and relaxation, to give some seclusion for the users. To handle the partial visibility according to isovist results, the centre was designed with an outdoor theatre and fountain that create a dynamic space (Figure 11 (C; $6,7)$ ), as a gathering point visually connected with all the subspaces of the plaza, to somehow oppose the 'edge effect' in terms of people's spatial use.


Figure 11. (A) Ground plan of the proposal design, (B) design proposal principals: the grid oriented according to the angle of the most integrated and connected lines L1 and L2 (axialline map), (C) some 3D views of the proposed design. 


\subsection{Verification and syntactic valuation of the plaza design proposal}

This phase is aimed to evaluate syntactically the layout proposal, to check whether the spatial proprieties of different subspaces are relevant or not to the functional principles of the design, through three analyses using the Depthmap program: the Visibility Graph Analysis, the fewest-lines analysis and isovist.

Visibility Graph Analysis (VGA) generated the level of integration and connectivity; the former was measured considering only the boundary of the public plaza, and the latter measured within a 250-meter radius perimeter from the centre of El-Houria plaza (Figure 12).
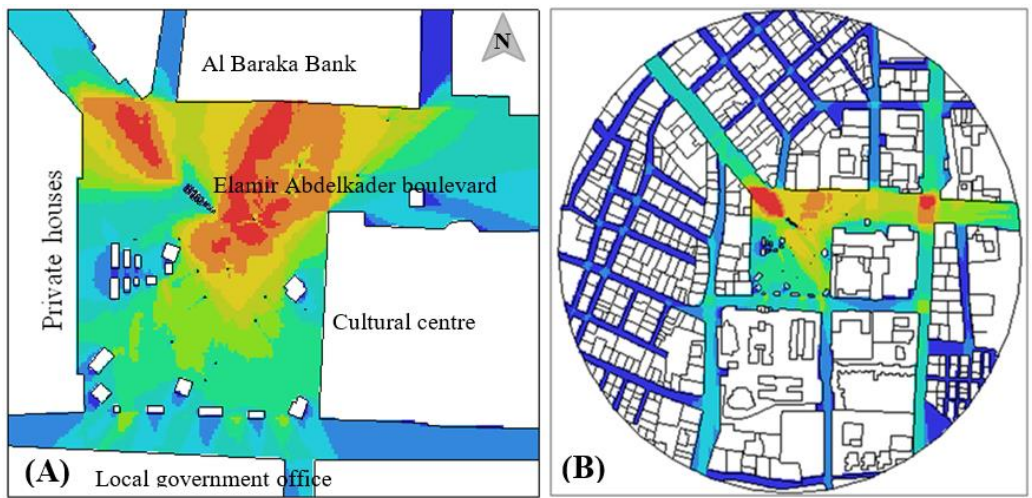

Figure 12. (A) Results of the VGA for the visual integration values of the proposal design. (B) The visual connectivity values of the proposal design. (Red (the darkest colour) $=$ high values / blue (lightest colour) $=$ lower values).

This analysis shows that the most integrated (34.02) and the most connected (more than 11,560) spaces are close to Elamir Abdelkader Boulevard, particularly in the Northeast part (Figure 12). Therefore, this area is the most visible and accessible and has connections with other spaces because of the total absence of visual obstacles and the presence of landmarks such as the memorial wall and the footbridge, which provides an excellent entry to the plaza as a visual access point.

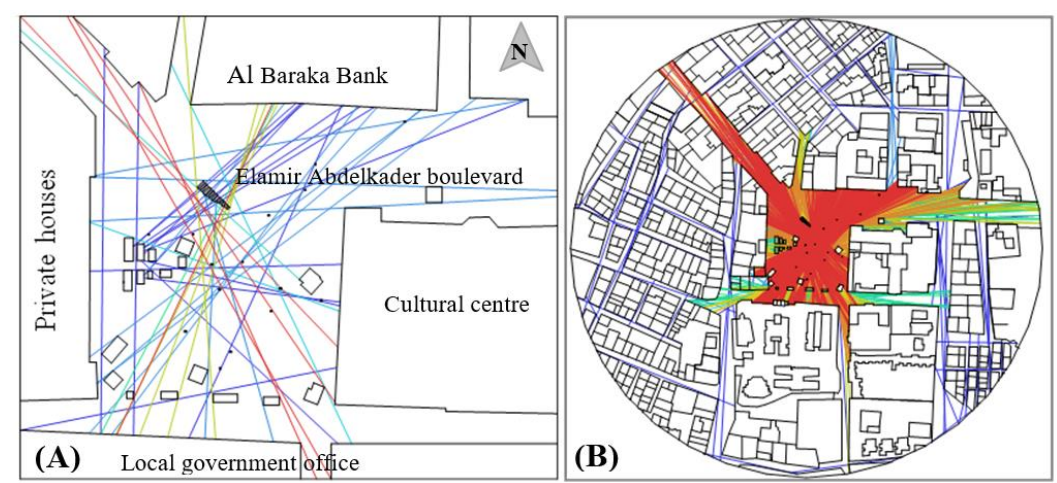

Figure 13. (A) Results of the fewest-lines analysis for the visual integration values of the design proposal. (B) The visual connectivity values of the design proposal. (Red (the darkest colour $)=$ high values $/$ blue (lightest colour) $=$ lower values . 
As can be seen from Figure 13, the segregated spaces are fewer than the integrated spaces, and the majority of the spaces are more connected (more than 2,240) with each other and with other surrounding urban spaces because there is no separation between them, except the area to the west next to the private houses, which is characterized by a density of trees to create a visual obstacle to the houses (privacy).

Isovist analysis is generated to measure the visual field that can be seen by a user from two points, one as an access point from the esplanade (isovist A), and the other in the centre of the plaza as a gathering space (isovist B).


Figure 14. Isovists generated within the plaza layout design proposal: (A) from the esplanade, (B) from the centre of the plaza.

The isovist (A) indicates that the plaza is partially visible from the esplanade (Figure 14 (A)), due to the presence of certain obstacles such as trees and the memorial wall. However, this space provides a greater indivisibility with the surrounding of the plaza that would enhance the effect of visual access. Isovist (B) indicates that the plaza is visible in all directions except the esplanade because of the presence of trees that conceal the view (Figure 14 (B)). However, each of these two spaces (A and B) gives a large visual field as can be seen by the shape of the polygon, it seems to be a good result since the existing literature shows that people gather where they can control and see other people (Campos, M. B. d. A. \& Golka, 2005; Whyte, 1980) and the spaces for sitting and activities need some seclusion (edge effect).

\section{DISCUSSION OF THE RESULTS}

The confrontation of the visibility analysis results of El-Houria plaza and the design proposal of this plaza, made from the syntactic approach, show that the most integrated and connected spaces in the El-Houria plaza are the same as those in the proposal design, but with a remarkable enlargement, as well as most of the segregated spaces of the current layout having disappeared in the proposed layout and having become more connected with all the subspaces. The isovist analysis also shows that the visual field (polygon) generated from the same points in both positions is more important (larger and more spiky) in the proposal than in the existing plaza layout, indicating deeper views. For this purpose, it can be said that the proposed design of this plaza has reached a higher level of visibility and all 
its subspaces are interconnected visually, in addition to the surrounding urban space, except for the western zone next to the private houses, which is characterized by a density of trees as sitting spaces. As a result, it is good to have some seclusion according to the literature that people prefer occupying the edges to have views, with keeping the privacy.

\section{CONCLUSION}

Urban plazas as one of the significant open public space types is a fundamental element for liveable cities because without public spaces it is impossible to establish a physical and mental connection between people and the urban environment. Designing public urban spaces, i.e. urban plazas, requires more understanding and attention to people's behaviour. To be functional and responsive to people needs, the design of such spaces has to consider primarily the visibility as a principal feature in the space layout and all its components (Bada, 2012).

The results of all the methods of the El-Houria plaza analysis, and the confrontation of the visibility analysis of El-Houria plaza and the design proposal, show that the spatial use of the plaza is highly dependent on visibility, accessibility and connectivity to the surroundings, as key parameters to good functioning; visual access is a decisive factor in public space use (Montello, 2007). The results also indicate that there is a high correlation between the human behaviour and the syntactic properties in selecting places to do definite activities. Furthermore, it is shown how visibility becomes the principal feature in the layout proposal of this plaza.

This study has considered space syntax as both theory and method, the most appropriate tool to investigate the problems inherent to the use of urban plazas linked to visibility and accessibility. Mainly, space syntax seems to be an effective tool for analysis and design when coupled with behavioural, perceptual and cognitive analysis methods. Nevertheless, the only disadvantage is the syntactic measures rely on the two-dimensional space. This represents a field of research in which many researchers collaborate in order to develop methods and syntactic parameters of threedimensional space to gain a better understanding of human behaviour in architectural and urban space.

In conclusion, this study has allowed us to show how space syntax could be a remarkable tool to be integrated into the design process. Besides that, this study has shown how syntactic properties, i.e. isovists (visual fields), of the plaza could be integrated into the design process and manipulated (enhanced) by the layout design and the pattern of its urban and architectural components.

\section{REFERENCES}

Alexander, C. (1977). A Pattern Language: Towns, Buildings, Construction. New York: Oxford university press.

Bada, Y. (2012). "The Impact of Visibility on Visual Perception and Space Use: The Case of Urban Plazas in Biskra". Université Mohamed Khider-Biskra. 
Baker, R. G. (1997). "Stimulation Theories; Arousal Theory, Overload Theory and Restricted Environmental Stimulation". Environmental Psychology: Principles and Practices (pp. 6-15). Boston: Allyn and Bacon.

Campos, B. (1997). "Strategic Spaces: Patterns of Use in Public Squares of the City of London". Proceedings of the First International Space Syntax Symposium (University College London).

Campos, M. B. d. A., \& Golka, T. (2005). "Public Spaces Revisted: A Study of the Relationship between Patterns of Stationary Activity and Visual Fields". Proceedings of the 5th Space Syntax Symposium, Delft: University of Technology, pp. 545-553.

Dursun, P. (2007). "Space Syntax in Architectural Design". Proceedings of the 6th International Space Syntax Symposium, Istanbul, pp. 01-56.

Gehl, J. (1987). Life between Buildings: Using Public Space. Washiton D. C.: Island press.

Hillier, B. (1996). Space Is the Machine: A Configurational Theory of Architecture. Cambridge: Cambridge University Press.

Hillier, B. (2005). "Between Social Physics and Phenomenology: Explorations Towards an Urban Synthesis?". Proceedings of the 5th International Space Syntax Symposium, Delft, pp. 3-23.

Husnéin, A. (2017). "The Evolving Role of Modern Urbanistic Heritage in Shaping Sustainable Public Realm". International Review for Spatial Planning Sustainable Development, 5(3), 5-24.

Krier, R., \& Rowe, C. (1979). Urban Space. Academy Editions London.

Lang, J. (1987). Creating Architectural Theory: The Role of Behavioural Sciences in Environmental Design. New York: Van Nostrand Reinhold.

Lynch, K. (1976). The Image of the City. Paris: Dunod.

Montello, D. R. (2007). "The Contribution of Space Syntax to a Comprehensive Theory of Environmental Psychology". Proceedings of the 6th International Space Syntax Symposium, Istanbul, $\quad$ pp. 1-12. $\quad$ Retrieved from http://www.spacesyntaxistanbul.itu.edu.tr/papers/invitedpapers/daniel_montello.pdf.

Moughtin, C. (2003). Urban Design: Street and Square. Oxford: Architectural Press.

Özyavuz, M. (2013). "Designing Urban Squares". Advances in Landscape Architecture: IntechOpen. Retrieved from http://www.intechopen.com/books/advances-inlandscapearchitecture/designingurbansquares.

Perin, C. (1970). With Man in Mind: An Introduction Prospectus for Environmental Design. Massachusetts, Cambridge: The MIT Press.

Trova, V. (2007). "Designing for Human Encounter: Urban Design and the Politics of Visibility". Proceedings of the Sixth International Space Syntax Symposium, ITU Faculty of Architecture, Istanbul, pp. 1-14.

Trova, V., Hadjinikolaou, E., Xenopoulos, S., \& Peponis, J. (1999). "The Structure of Public Spacein Sparsely Urban Areas". Proceedings of the Second International Space Syntax Symposium, Brazilia, Brazil, pp. 1-12.

Turner, A. (2004). Depthmap 4: A Researcher's Handbook. London: Bartlett School of Graduate Studies, University College London.

Whyte, W. H. (1980). The Social Life of Small Urban Spaces. Washington, D.C.: Conservation Foundation.

Whyte, W. H. (1988). City: Rediscovering the Center. Garden City, New York: Doubleday. 